\title{
Do social restriction policies responding to COVID-19 pandemic associated with economic growth?
}

\author{
Heru Fahlevi ${ }^{*}$, Teuku Rizky Saevic ${ }^{2}$, Jalaluddin Jalaluddin ${ }^{1}$ and Muslim A Djalii ${ }^{3}$ \\ ${ }^{1}$ Accounting Department, Faculty of Economics and Business, Syiah Kuala University, 23111 Banda Aceh, Indonesia \\ ${ }^{2}$ Economics Department, Faculty of Economics and Business, Syiah Kuala University, 23111 Banda Aceh, Indonesia \\ ${ }^{3}$ Management Department, Faculty of Economics and Business, Syiah Kuala University, 23111 Banda Aceh, Indonesia
}

\begin{abstract}
The purpose of the study is to examine the statistical relationship between restriction and containment policies in respond to COVID-19 pandemic and the countries' economies. This study also maps countries based on their economic growth and the public mobilization restriction policies. The GDP growth was extracted from the economy prognosis from the International Monetary Fund. To determine the restriction policy level, the stringency index (SI) produced by the Oxford COVID-19 Government Response Tracker (OxCGRT) was used. The SI is between $0-100$ in a range that is computed based on containment and closure policies, for instance, stay at home requirement and closure of public facilities, and public events. The SI used in this study is the average score of the first 3 months after the WHO declared COVID19 as a pandemic (11 March 2020). Using the Spearman correlation test to investigate the relationship between GDP growth and restriction level in 166 countries, this study demonstrates a negative association between GDP growth and the SI. This means that countries that imposed stricter policies in the early COVID-19 pandemic tend to have higher GDP contraction. However, the correlation coefficient is relatively weak $(-0.200)$, and thus, every government has the opportunity to reduce the unintended outcomes of restriction policies by providing economy and financial support packages for businesses, people, and other affected groups.
\end{abstract}

\section{Introduction}

The spread of the coronavirus disease of 2019 (COVID19) has reached almost every country in the world. Its effect is multisectoral and affects governments, industries, and the people, particularly due to the slow down economic activity resulting [1]. The COVID-19 requires governments to take immediate actions to prevent further outbreaks for a relatively unknown period of time.

Responding to the COVID-19 pandemic and rapid increase of infected cases and death, most countries across the globe have adopted containment, social distancing, and closure policies. The policies include the closure of public facilities (school, offices, and restaurants), working from home, quarantines and even lockdown [2]. These policies often vary in terms of duration, and level of restrictions [3]. Governments tend to strengthen the policy when the case number has risen and relax the restriction when the case starts to decline. This reflects a national dilemma whether to save lives or the country's economy.

It is indeed that restriction policy may reduce COVID-19 spread (see for example [1]). However, this policy is widely questioned and even rejected by some groups of citizens [4]. Some countries, for example, China, Australia, and Vietnam imposed a national lockdown, while the other countries, for example,
Indonesia adopt softer restriction rules for the sake of economic stability ([5] [6]). Despite its effectiveness in containing the spread of COVID-19, experts believe that the restriction policies cost the country economy [4] [7] [8]. [9] and [10] argue that the policies lead to economic crisis and recession as the social distancing contributes to economic and financial shutdowns.

Research on the impact of COVID-19 and the related government policies for economy and finance are still limited and demonstrated mixed findings. [11] investigated the impact of duration of national lockdown on public health and economy of 6 countries in Europe. The study revealed that the length of national lockdown has a negative influence on economic growth. In the same vein, [12] investigated the impact of lockdown policy on the African countries' economies. They revealed that the global pandemic and the subsequent lockdown led to a GDP decline of 34 percent, a reduction of wage earnings especially lower-educated workers.

In contrast, [13] studied the influence of the pandemic and its subsequent lockdown on the daily stock returns of Vietnamese companies. This study uncovered unexpected results that show a positive influence of imposed lockdown on the stock market. [13] believes that the positive influence mirrors enhanced investors' confidence and trust in the

\footnotetext{
* Corresponding author: hfahlevi@unsyiah.ac.id
} 
government's strategies and capacity dealing with the pandemic.

As there is no consensus in terms of the results, this study aims to examine the statistical relationship between public mobilization policies and countries' economies. Besides, cross countries-based study that examined the correlation between social restriction policies and the country economy is still very scanty.

This study is required to understand how the COVID-19 policies affect the country economy and to determine the optimum level of restriction to minimize its unintended impact on the economy. Finally, this study also maps countries based on their economic growth and public mobilization restriction policy amid the COVID-19 pandemic.

\section{Research method}

Data were collected from published reports and databases (secondary data). The annual GDP growth refers to a change in GDP between 2019 and 2020 (prediction). The GDP growth was extracted from the economic prognosis of the International Monetary Fund [14]. To determine the restriction policy level, the stringency index (SI) produced by the Oxford COVID19 Government Response Tracker (OxCGRT) [3] was used.

SI is between $0-100$ in a range that is computed based on containment and closure policies. There are 8 dimensions to measure the stringent level of restriction policies. These include the closure of school and office, cancelation of public events, gathering restrictions, transportation arrangement, stay at home policy, restriction of internal movement, and international travel ban. The SI used in this study is the average score of the first 3 months after the WHO declared COVID19 as a pandemic (11 March 2020).

This study used the Spearman correlation test to investigate the correlation between GDP growth and restriction level in 166 countries. The Spearman correlation coefficient $(\rho S)$ was adopted because our data do not meet the assumption of the bivariate normal distribution [15]. This data analysis method has been widely used to compare two unrelated datasets (see for instance, [16], [17]).

\section{Results and discussion}

The results consist of descriptive statistic results and correlation test results. Both provide corroborating evidence on the relationship between economic performance and restriction policies.

\subsection{Descriptive statistic results}

GDP growth has declined during the first year of pandemic. Table 1 exhibits that the average GDP growth in 2020 is -6.23 . It indicates that in general, most countries around the world experienced a negative economic growth in 2020 that is related with the pandemic. Some countries gained positive GDP growth, while the other experienced economic turmoil.

In addition, the data shows that the average SI is 70 (medium to very stringent). Some countries have adopted a relatively very light restriction policy during the first three months of the COVID-19 pandemic (14).

Table 1. Results of descriptive statistics.

\begin{tabular}{|l|c|c|c|c|}
\hline \multicolumn{1}{|c|}{ Variables } & $\mathbf{N}$ & Mean & $\begin{array}{c}\text { Maximal } \\
\text { value }\end{array}$ & $\begin{array}{c}\text { Minimum } \\
\text { value }\end{array}$ \\
\hline GDP_Growth & 166 & -6.23 & 31.54 & -64.33 \\
\hline Stringency index & 166 & 70 & 95 & 14 \\
\hline
\end{tabular}

Table 2 exhibits divergent SI but a similar economic performance across continents. The economy of South American and Oceania countries has been affected more severed compared to other countries in Africa and Europe. This may be linked to a more stringent polices adopted by South American countries than Oceania countries.

Table 2. Results of descriptive statistics.

\begin{tabular}{|l|c|c|}
\hline \multicolumn{1}{|c|}{ Countries } & $\begin{array}{c}\text { GDP } \\
\text { growth }\end{array}$ & SI \\
\hline Africa & $-4.84 \%$ & 67 \\
\hline Asia & $-5.75 \%$ & 70 \\
\hline Europe & $-5.35 \%$ & 71 \\
\hline North America & $-8.99 \%$ & 75 \\
\hline Oceania & $-7.06 \%$ & 55 \\
\hline South America & $-11.51 \%$ & 80 \\
\hline
\end{tabular}

Furthermore, some countries' economies were more severely affected by COVID-19. Table 3 shows 10 countries with the smallest GDP growth in 2020. Lebanon and Libya adopted relatively less stringent SI policies and their economic performance was the lowest. Most of the countries adopted medium to high restriction policies.

Table 3. Top 10 countries with the lowest 2020 GDP growth

\begin{tabular}{|l|c|c|}
\hline \multicolumn{1}{|c|}{ Countries } & GDP growth & SI \\
\hline Lebanon & $-64.33 \%$ & 78 \\
\hline Libya & $-45.26 \%$ & 88 \\
\hline Suriname & $-31.35 \%$ & 73 \\
\hline Seychelles & $-27.44 \%$ & 59 \\
\hline Fiji & $-27.28 \%$ & 74 \\
\hline Brazil & $-25.85 \%$ & 74 \\
\hline Zimbabwe & $-25.12 \%$ & 75 \\
\hline Venezuela & $-24.00 \%$ & 80 \\
\hline Iraq & $-22.61 \%$ & 89 \\
\hline Zambia & $-21.72 \%$ & 46 \\
\hline
\end{tabular}

Moreover, Table 4 shows countries that adopted the highest level of restriction policy to combat COVID19. All of the countries experienced negative GDP growth. Compared to other countries on the list, Libya and Iraq have relatively lower GDP growth $(-45.26 \%$ 
and $-22.61 \%$ ) as they imposed strictest restriction policies. Meanwhile, other countries experienced better economic performance with milder restriction policies.

Table 4. 10 countries with the most stringent restriction policy.

\begin{tabular}{|l|c|c|}
\hline \multicolumn{1}{|c|}{ Countries } & GDP growth & SI \\
\hline Honduras & $-3.76 \%$ & 95 \\
\hline Philippines & $-2.50 \%$ & 92 \\
\hline Peru & $-15.16 \%$ & 91 \\
\hline Guatemala & $-0.66 \%$ & 91 \\
\hline El Salvador & $-8.29 \%$ & 90 \\
\hline Bolivia & $-5.47 \%$ & 90 \\
\hline Iraq & $-22.61 \%$ & 89 \\
\hline Puerto Rico & $-9.00 \%$ & 89 \\
\hline Libya & $-45.26 \%$ & 88 \\
\hline Kuwait & $-19.74 \%$ & 88 \\
\hline
\end{tabular}

\subsection{Correlation test results}

Spearman correlation test was performed to examine the association between GDP growth and SI. Table 5 shows a significant level is 0.01 , smaller than 0,05 . Therefore, this study demonstrated a significant association between GDP growth and SI.

Table 5. Results of Spearman correlation test.

\begin{tabular}{|c|c|c|}
\hline Variables & $\begin{array}{c}\text { Correlation } \\
\text { coefficient }\end{array}$ & Sig. (2 tailed) \\
\hline $\begin{array}{c}\text { GDP_growth and } \\
\text { SI }\end{array}$ & -0.265 & 0.01 \\
\hline
\end{tabular}

Moreover, the results of this study revealed a negative association between GDP growth and SI. This means that countries that implemented stricter policies in the early COVID-19 pandemic tend to have higher GDP contraction. However, the correlation coefficient is relatively weak $(-0.265)$ and thus, the economic damage can be mitigated using economic and fiscal incentives and optimizing the duration and level of restrictions. Before imposing lockdown, for instance, governments should have effective scenarios that minimizes the economic impact of the lockdown. The scenarios may include a different of lockdown intensity and duration across the country region and people group. For instance, a longer lockdown plan is imposed for elderly and children and for region with the highest case increase and the highest population density.

\subsection{Discussion}

Most governments are in a dilemmatic situation as they need to impose restriction policy to contain the rising number of infected cases and death while preventing the economy shutdown and its consequences. There is been a long debate on the impact of the restriction policies on a country's economy [18], and in some countries leads to people's resistance and demonstration.
The results of this study are consistent with the prior studies, for instance, [18] and [19]. The former found that restriction policy in 42 countries is an important driver of GDP growth [18]. The latter demonstrated that social distancing and other restriction policies explained divergent across 46 countries in the first semester of 2020 [19].

Moreover, the results of this study contribute to the debate on restriction policies and their impact on the economy. The negative correlation between GDP growth and SI indicates the need for periodic assessment. Governments are required to save both economy and people live by determining equilibrium through lift restriction policies when the economy suffered at a certain point.

Finally, the restriction policies should be accompanied by financial assistance policies to lighten the burden faced by industries and people's economies. The policies may include tax support, credit access financial support for workers and companies, and interest cuts [20].

Few studies demonstrate early evidence on the effectiveness of some government interventions during the lockdown. For instance, [21] revealed that the payroll protection program (a bridge loan program) and Main Street Lending Program can prevent corporate bankruptcies. Meanwhile, [22] evaluated the effectiveness of government support packages for smallmedium enterprises in Russia in the COVID-19 pandemic. They found that the support policy is more effective if the government provides a comprehensive package rather than one type of government support. For instance, SMEs should receive tax, administrative and financial support collectively to survive in this pandemic era.

\section{Conclusions}

This study confirms that the restriction of public mobilization and other related strategies adapted by governments amidst the COVID-19 pandemic was negatively correlated with economic growth. However, the correlation is relatively weak. This suggests that the containment and closure policies do not always lead to economic decline especially if governments adopt economic policies that ease the burden faced by the industry, companies, and the people.

Each government, thus, should prepare anticipation policies to mitigate the COVID-19 related policies on the country and people's economy. Moreover, any support economy and financial package not only is required to save people and the country economy but also to ensure that people adherend to the restriction policies. Further studies are imperative to facilitate better understanding and empirical evidence on the trade-off between economy and health in the current difficult situation. More importantly, research on finding the most effective combination of economic and social supports is required as the pandemic can be longer than we expect and it can occur again in the future. 


\section{References}

1. M. Chaudhary, P. R. Sodani, and S. Das, J. Health Manag. 22, 169 (2020)

2. A. Atalan, Ann. Med. Surg. 56, 38 (2020)

3. T. Hale, N. Angrist, R. Goldszmidt, B. Kira, A. Petherick, T. Phillips, S. Webster, E. Cameronblake, L. Hallas, S. Majumdar, and H. Tatlow, Nat. Hum. Behav. 5, 529 (2021)

4. R. K. Biswas, S. Huq, and A. Afiaz, Int. J. Heal. Policy Manag. 9, 488 (2020)

5. N. Nurcahyono, A. N. Hanum, and F. Sukesti, J. Din. Akunt. Dan Bisnis 8, 47 (2021)

6. R. Kuswanto, J. Din. Akunt. Dan Bisnis 8, 105 (2021)

7. M. Mckee and D. Stuckler, Nat. Med. 26, 640 (2020)

8. P. Boettke and B. Powell, Sourthern Econ. J. 1 (2021)

9. P. Ozili and A. Thankom, Spillover of COVID-19: Impact on the Global Economy (2020)

10. M. C. Howard, Pers. Individ. Dif. 168, 110335 (2021)

11. M. Coccia, J. Econ. Libr. 3, 100 (2016)

12. C. Arndt, R. Davies, S. Gabriel, L. Harris, K. Makrelov, S. Robinson, W. Simbanegavi, D. Van Seventer, and L. Anderson, Impact of Covid-19 on the South African Economy An Initial Analysis (2020)

13. D. L. T. Anh and C. Gan, J. Econ. Stud. 48, 836 (2020)

14. International Monetery Fund, (2021)

15. R. Artusi, P. Verderio, and E. Marubini, Int. J. Biol. Markers 17, 148 (2002)

16. E. Fallan, J. Account. Organ. Chang. 11, 247 (2015)

17. H. Fahlevi, M. Indriani, and R. S. Oktari, Jamba J. Disaster Risk Stud. 11, 1 (2019)

18. M. König and A. Winkler, Intereconomics 56, 32 (2021)

19. M. Koenig and A. Winkler, CEPR Covid Econ. $132(2020)$

20. X. Cirera, M. Cruz, E. Davies, A. Grover, L. Iacovone, J. E. L. Cordova, D. Medvedev, F. O. Maduko, G. Nayyar, S. Reyes Ortega, and J. Torres, World Bank Res. Obs. 36, 41 (2021)

21. V. Elenev, T. Landvoigt, and S. Van Nieuwerburgh, SSRN Electron. J. (2020)

22. E. Razumovskaia, L. Yuzvovich, E. Kniazeva, M. Klimenko, and V. Shelyakin, J. Open Innov. Technol. Mark. Complex. 6, (2020) 